\title{
Abnormal Seedlings Emerged during Embryo Rescue and Its Remedy for Seedless Grape Breeding
}

\author{
Wei $\mathrm{Ji}^{1,2,3}$, Zhiqian $\mathrm{Li}^{1,2,3}$, Wenkong Yao ${ }^{1,2,3}$, Peijie Gong ${ }^{1,2,3}$, and Yuejin Wang ${ }^{1,2,3 *}$ \\ ${ }^{1}$ College of Horticulture, Northwest A \& F University, Yangling 712100, Shaanxi, PR China \\ ${ }^{2}$ Key Laboratory of Horticultural Plant Biology and Germplasm Innovation in Northwest China, \\ Ministry of Agriculture, Yangling 712100, Shaanxi, PR China \\ ${ }^{3}$ State Key Laboratory of Crop Stress Biology in Arid Areas, Northwest A\&F University, Yangling 712100, Shaanxi, PR China
}

\begin{abstract}
The abnormal seedlings, a common physiological anomalies, emerged during embryo rescue severely restricted grape breeding. To enhance the efficiency of the seedless grape breeding by reducing the production of abnormal seedlings in the course of embryo rescue, we investigated the effects of genotype, media type, embryo style, pre-chilling on the deformity rate of the abnormal seedlings during embryo rescue. The abnormal seedlings were firstly classified into seven categories based on their morphology. Our results indicated that the emergence of abnormal seedlings was highly dependent on the female parent genotype. Polyembryony was advantageous to diminish the number of abnormal plantlets and the germination rate of embryo was $100 \%$. We also found that pre-chilling treatment could reduce the number of abnormal plantlets and promote the embryo germination. The abnormal plantlets were reduced significantly by the addition of $\mathrm{ZnSO}_{4} 10 \mu \mathrm{mol} \cdot \mathrm{L}^{-1}$ or mashed-banana $500 \mathrm{mg} \cdot \mathrm{L}^{-1}$ to either embryo development or germination media. Transferring the abnormal seedlings onto the suitable fresh media in 4 weeks after embryo germination provided an effective way to transform them into normal seedlings.
\end{abstract}

Additional key words: deformity seedlings, embryo rescue, polyembryony, seedless grapes, stenospermocarpy

\section{Introduction}

The quality of seedlings through embryo rescue determines whether they would survive. The unhealthy developed seedlings may survive in the in vitro conditions, however, its morphology and functional defects eventually lead it to death after transplanting. Obviously, the way to discard the abnormal seedlings is undesirable, but the key is appropriate corrective and prevention.

Since Steward (1958) got somatic embryos from carrot callus and suspension cell system, the plant tissue culture technology has been rapidly developed. Earlier in 1982, Ramming and Emershad (1982) first reported stenospermic grapes could generate plants via ovule culture. It enhanced the application of this in vitro method in seedless grape breeding. Since then, this embryo rescue technique has been widely applied to embryo germination of seedless grape cultivars in cross-breeding program (Bharathy et al., 2005; Emershad and Ramming, 1982, 1984; Emershad et al., 1989; Gray et al., 1990; Gribaudo et al., 1993; Park et al., 1999; Ponce et al., 2000; Sharma et al., 1996; Singh et al., 2011; Spiegle-Roy et al., 1985; Tang et al., 2009; Tian et al., 2008). In vitro embryo rescue in grape breeding project assures breeding efficiency by curtailing 6 to 8 years in the development of seedless grape cultivars (Singh et al., 2011). However, in the process of embryo rescue hybrid seedlings, abnormal seedlings occurred in a great chance and severely limited the grape breeding process in embryo rescue. Therefore, to find the causes of seedlings abnormality and to overcome them will be a very important task in grape breeding.

\footnotetext{
*Corresponding author: wangyj@nwsuaf.edu.cn

※ Received 4 August 2012; Revised 29 May 2013; Accepted 29 May 2013. This research was supported by Project of Special Fund for Agro-scientific Research in the Public Interest (200903044) and by the earmarked fund for China Agriculture Research System for grape industry (Grant No. CARS-30-yz-7). The study work was performed in College of Horticulture, Northwest A \& F University, Yangling 712100, Shaanxi, P.R. China and Key Laboratory of Horticultural Plant Biology and Germplasm Innovation in Northwest China, Ministry of Agriculture, Yangling, Shaanxi 712100, P.R. China and State Key Laboratory of Crop Stress Biology in Arid Areas, Northwest A\&F University, Yangling 712100, Shaanxi, P.R. China.
} 
In embryo rescue of seedless grapes, the embryo need a period of culturing in ovule, and then cut the ovule to continue fostering the naked embryo to promote the germination and seedling. However, not all embryos can germinate to normal seedlings. Our previous studies demonstrated that there was a number of deformity seedlings produced after embryo germination which was apparently unfavorable to a grape breeding (Tang et al., 2009; Tian et al., 2008). This phenomenon is consistent with other reports (Emershad et al., 1984, 1989; Liu et al., 2003; Valdez, 2005). So far, the limiting factors in the inducement of the deformity seedlings remain unknown. In the current study, we investigated the effects of genotype, media type, embryo style, pre-chilling on the deformity rate with the aim to enhance the seedless grape breeding efficiency by decreasing and preventing the number of the deformity seedlings in the process of embryo rescue. The preliminary transformation test was also conducted.

\section{Materials and Methods}

\section{Plant Materials}

All grape plants were grown in a vineyard of Xinjiang Development and Research Center of Grapes and Melons, located in Shanshan County, Xinjiang Uygur Autonomous Region of PR China. Eight to ten years old plants were used and trained to trellis with a planting density of 1.0 $\mathrm{m} \times 4.0 \mathrm{~m}$. Emasculation (Fig. 1A) was conducted 3 days before anthesis, followed by washing and bagging of the inflorescence. One day later, artificial pollination (Fig. 1B) was conducted using a mass of cotton with pollens, collected earlier from the male parents 2 days before their blooming and preserved at $-4^{\circ} \mathrm{C}$ for use (Tian et al., 2008), followed by immediate bagging and marking of the inflorescence (Fig. 1C).

\section{Embryo Rescue}

Immature fruits were collected and surface-sterilized with $70 \%$ ethanol for $30 \mathrm{~s}$, followed by $0.1 \% \mathrm{HgCl}_{2}$ for $6 \mathrm{~min}$ and three washes in sterilized water. Ovules were excised and cultured in Erlenmeyer flasks containing embryo formation medium (Table 3), each flask containing 30-35 ovules (Fig. 1D). The $\mathrm{pH}$ of the medium was adjusted to 6.0 before autoclaving. After 9 to 10 weeks of in vitro culture, embryos were excised from the ovules under a stereomicroscope, and then transferred onto embryo germination media on the base of WPM, woody plant medium (Lloyd and McCown, 1980) (Table 4). After 4 weeks of culture, the germinated embryos were counted and transferred to the rooting media (MS + IBA $0.1 \mathrm{mg} \cdot \mathrm{L}^{-1}+6$-BA $0.4 \mathrm{mg} \cdot \mathrm{L}^{-1}$ ) for plant regeneration. And in the same time, the numbers of normal seedlings and abnormal seedlings, embryo germination rate, deformity rate of germination seedlings were recorded. All cultures were grown at a temperature of $25^{\circ} \mathrm{C}$ under a 16 -h photoperiod with a light intensity of $40 \mu \mathrm{E} \cdot \mathrm{s}^{-1} \cdot \mathrm{m}^{-1}$ provided by cool-white fluorescent light. Subculture was performed every 4 weeks. The transformation test of the deformity seedlings were carried

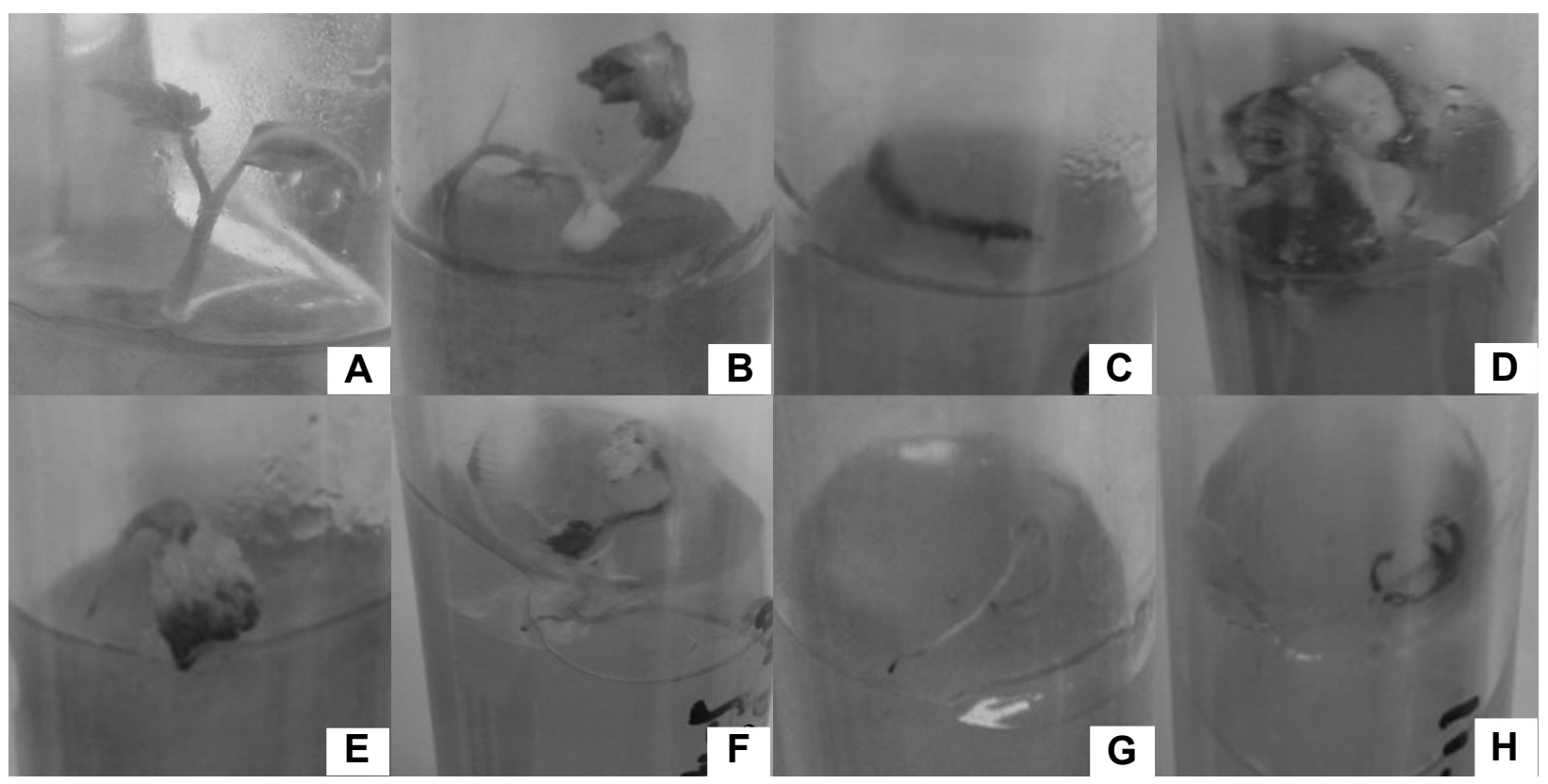

Fig. 1. Abnormal seedlings on an embryo germination media. (A) An normal seedling; (B) Epicotyl appears only one cotyledon; (C) Neither cotyledon nor shoot; (D) The cotyledons were distorted fold-like; (E) The formation of the albino seedlings in the process of differentiation; $(F)$ Hypocotyls formed short root, but no cotyledon; $(G)$ Epicotyl formed cotyledons, but no root; (H) The plantlet early development-stopped. 
out on the base medium of 2MS (double concentrations of MS) (Table 5).

\section{Results}

\section{Classification of Abnormal Seedlings}

In the case of plants, the embryo is a multicellular structure endowed with potentiality to form a new plant. The embryo is essentially a bipolar structure with root and shoot primordial structures (Sharma et al., 1996). After embryo germination, not all of the embryos formed normal seedlings. The deformity seedlings could be divided into the following categories: 1) epicotyl appears only one cotyledon; 2) neither cotyledon nor shoot; 3) the cotyledons were distorted fold-like; 4) the formation of the albino seedlings in the process of differentiation; 5) hypocotyls formed short root, but no cotyledon; 6) epicotyl formed cotyledons, but no root; 7) the plantlet early developmentstopped (Fig. 1). The occurrence and proportion of each variety of malformation seedlings are random and unfixed.

\section{Effect of Different Genotype on the Abnormal Plantlet Formation}

The responses of different cross combinations to the formation of abnormal plantlets by embryo rescue were displayed in Table 1. Among the different genotypes, proportions of abnormal plantlets production were significantly different, ranging from $58.0 \%$ to only $2.8 \%$. The germinated embryos of "Ruby Seedless $\times$ Black Olympia" produced much more abnormal plantlets $(50.3 \%)$ than "Big black $\times$ Black Olympia" $(2.8 \%)$. Similarly, the proportions of abnormal plantlets of cross "Blush Seedless $\times$ Shuangyou" was $50.7 \%$, which was much higher than that of "Pink Seedless $\times$ Shuangyou" $(13.0 \%)$. These results indicated that the formation of abnormal seedlings was mainly determined by the female parent genotype rather than that of the pollen parents.

\section{Effect of Polyembryony on the Abnormal Plantlet Formation}

There was polyembryony occurred in the cross combinations "Ruby Seedless $\times$ Black Olympia", "Ruby Seedless selfpollination" and "Otilia Seedless self-pollination" and "Superior Seedless self-pollination" by embryo rescue (Fig. 2), even though the appearance of polyembryony was in a slim chance, which no more than $5 \%$, no matter in any cross combinations. Especially to deserve to be mentioned, it was advantageous to diminish the number of abnormal plantlets by successive transferring the single embryo to fresh germination media (WPM + 6-BA $0.2 \mathrm{mg} \cdot \mathrm{L}^{-1}+$ mashed-banana 500

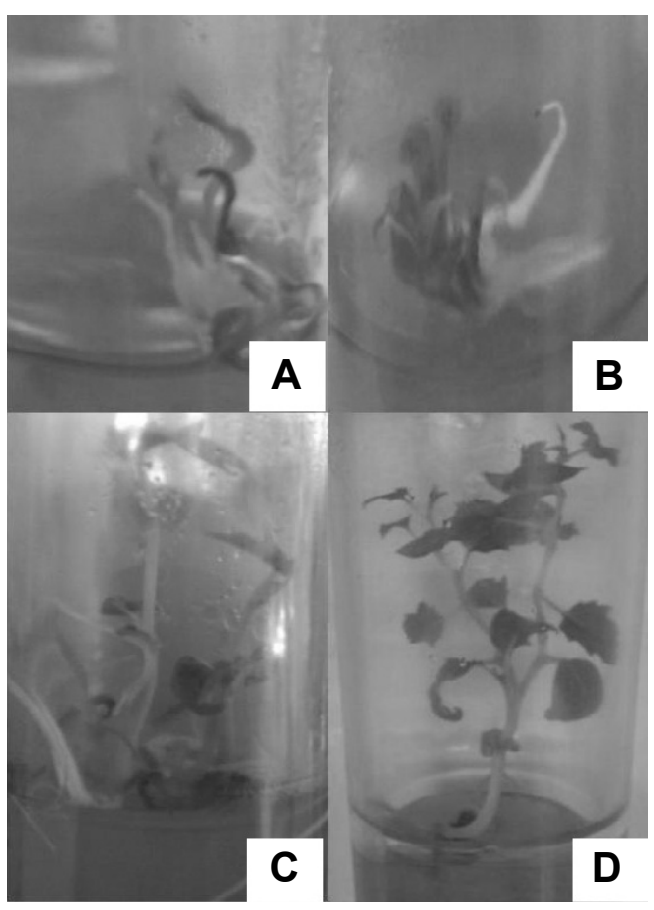

Fig. 2. Polyembryony germination: (A) Four days after polyembryony transferring onto germination media; (B) One week after polyembryony transferring onto germination media; (C) Two weeks after polyembryony transferring onto germination media; (D) One month after transferring one embryo of polyembryony to fresh media.

Table 1. Effect of different crosses on the abnormal plantlet formation (means $\pm S D$ ).

\begin{tabular}{|c|c|c|c|c|c|c|}
\hline \multirow{2}{*}{ Crosses } & \multirow{2}{*}{$\begin{array}{c}\text { No. of } \\
\text { embryos } \\
\text { cultured }\end{array}$} & \multirow{2}{*}{$\begin{array}{c}\text { No. of } \\
\text { embryos } \\
\text { germinated }\end{array}$} & \multicolumn{2}{|c|}{ Normal plantlets } & \multicolumn{2}{|c|}{ Abnormal plantlets } \\
\hline & & & No. & $\%$ & No. & $\%$ \\
\hline Ruby Seedless self-pollination & 124 & $112 \pm 9.6 b^{2}$ & $47 \pm 5.3 a$ & $42.0 \pm 3.2 c$ & $65 \pm 6.6 a$ & $58.0 \pm 3.2 \mathrm{a}$ \\
\hline Blush Seedless self-pollination & 169 & $149 \pm 15.1 \mathrm{a}$ & $76 \pm 4.4 b$ & $51.5 \pm 7.4 \mathrm{c}$ & $79 \pm 7.5 b$ & $52.8 \pm 1.1 \mathrm{a}$ \\
\hline Ruby Seedless $\times$ Black Olympia & 93 & $82 \pm 5.6 \mathrm{~cd}$ & $39 \pm 7.9$ a & $47.4 \pm 8.3 c$ & $41 \pm 5.6 \mathrm{c}$ & $50.3 \pm 9.3 a$ \\
\hline Blush Seedless $\times$ Shuangyou & 102 & $91 \pm 3.6 c$ & $44 \pm 4.4 \mathrm{a}$ & $48.3 \pm 3.2 c$ & $46 \pm 1.7 c$ & $50.7 \pm 3.9 a$ \\
\hline Big Black $\times$ Black Olympia & 84 & $73 \pm 3.0 \mathrm{~d}$ & $72 \pm 3.0 \mathrm{~b}$ & $98.6 \pm 0.1 \mathrm{a}$ & $2 \pm 1.7 \mathrm{~d}$ & $2.8 \pm 2.5 b$ \\
\hline Pink Seedless $\times$ Shuangyou & 98 & $88 \pm 7.0 \mathrm{~cd}$ & $77 \pm 5.3 b$ & $88.1 \pm 12.3 b$ & $12 \pm 11.4 \mathrm{~d}$ & $13.0 \pm 11.4 \mathrm{c}$ \\
\hline
\end{tabular}

Means within a row followed by different superscripts are different at $P=0.05$ (t-test) by DPS software (v13.5).

${ }^{z}$ Data followed by different letters in the same column were significantly different at $P \leq 0.05$ by Duncan's new multiple range test. 
$\mathrm{mg} \cdot \mathrm{L}^{-1}$ ) and the germination rate of polyembryony was $100 \%$.

Effect of Pre-chilling on the Abnormal Plantlet Formation

The effect of pre-chilling treatment on the abnormal seedlings in embryo rescue also investigated (Table 2). The results indicated that the low-temperature treatment reduced the occurrence of abnormal seedlings. The percentage of abnormal seedling rate was $36.0 \%$, which was significantly lower than that of the control (46.9\%). Moreover, we found that lowtemperature treatment increased the embryo germination rate. So it was benefit for promoting the efficiency of embryo rescue.

Effect of different media on the abnormal plantlet formation

To investigate the effect of different media on the abnormal plantlet formation, four different embryo development media styles were set in this experiment (Table 3). The results indicated that the addition of PGRs $\left(\mathrm{GA}_{3} 10 \mu \mathrm{mol} \cdot \mathrm{L}^{-1}+\right.$ IAA $\left.10 \mu \mathrm{mol} \cdot \mathrm{L}^{-1}\right)$ to $\mathrm{MS}$ media could adversely affect the embryo germination and stimulate the formation of abnormal plantlets. Conversely, the abnormal plantlets were reduced significantly by addition of $\mathrm{ZnSO}_{4}$ (24\%) or mashed-banana
(29\%) to MS in comparison with the control (43\%). Importantly, the highest embryo germination (91.4\%) was found when ovules were cultured in MS + mashed-banana $500 \mathrm{mg} \cdot \mathrm{L}^{-1}$.

Different embryo germination media influenced the formation of abnormal plantlet in varying degrees (Table 4). The highest rate of embryo germination (93.4\%) and the lowest rate of abnormal plantlet formation (32\%) were found when embryos were cultured in WPM +6 -BA $0.2 \mathrm{mg} \cdot \mathrm{L}^{-1}+$ mashed-banana $500 \mathrm{mg} \cdot \mathrm{L}^{-1}$. The addition of $\mathrm{ZnSO}_{4}$ could reduce the rate of abnormal plantlets (37\%), in comparison with WPM + 6-BA $0.2 \mathrm{mg} \cdot \mathrm{L}^{-1}(45 \%)$, but it had almost no effects on the embryo germination.

\section{The Conversion of the Abnormal Seedlings}

The occurrence probability of each variety of malformation seedlings were random and unfixed, we chose the abnormal seedlings emerged in a large proportion which epicotyl appears only one cotyledon (Fig. 1B) or the cotyledons were distorted fold-like (Fig. 1D). The conversion test was conducted in 4 weeks after embryo germination. There were three kinds of changes after the deformity seedlings transferred to the conversion medium: 1) induced the formation of normal

Table 2. Effect of pre-chilling on the abnormal plantlet formation of Ruby seedless self-pollination (means \pm SD).

\begin{tabular}{lcccc}
\hline \hline Treatment & Germination rate (\%) & Normal plantlets & Abnormal plantlets & Abnormal rate $(\%)$ \\
\hline $4^{\circ} \mathrm{C} 20 \mathrm{~d}$ & $89 \pm 1.7 \mathrm{a}^{\mathrm{z}}$ & $57 \pm 4.0 \mathrm{a}$ & $32 \pm 2.6 \mathrm{a}$ & $36.0 \pm 3.0 \mathrm{a}$ \\
control & $81 \pm 2.6 \mathrm{~b}$ & $43 \pm 3.6 \mathrm{~b}$ & $38 \pm 5.6 \mathrm{~b}$ & $46.9 \pm 6.9 \mathrm{~b}$ \\
\hline
\end{tabular}

Means within a row followed by different superscripts are different at $P=0.05$ (t-test) by DPS software (v13.5).

${ }^{z}$ Data followed by different letters in the same column were significantly different at $P \leq 0.05$ by Duncan's new multiple range test.

Table 3. Effect of different embryo development media on the abnormal plantlet formation (means \pm SD).

\begin{tabular}{lccc}
\hline \hline Media & Germination rate (\%) & Normal plantlets (\%) & Abnormal plantlets (\%) \\
\hline $\mathrm{MS}$ & $90.7 \pm 1.4 \mathrm{a}^{\mathrm{z}}$ & $57 \pm 5.3 \mathrm{~b}$ & $43 \pm 6.1 \mathrm{~b}$ \\
$\mathrm{MS}+\mathrm{ZnSO}_{4} 10 \mathrm{\mu mol} \cdot \mathrm{L}^{-1}$ & $89.3 \pm 2.2 \mathrm{a}$ & $76 \pm 8.9 \mathrm{a}$ & $24 \pm 3.0 \mathrm{c}$ \\
$\mathrm{MS}+\mathrm{GA3} 10 \mu \mathrm{mol} \cdot \mathrm{L}^{-1}+\mathrm{IAA} 10 \mu \mathrm{mol} \cdot \mathrm{L}^{-1}$ & $83.1 \pm 2.9 \mathrm{~b}$ & $44 \pm 7.0 \mathrm{c}$ & $56 \pm 7.9 \mathrm{a}$ \\
$\mathrm{MS}+$ mashed-banana $500 \mathrm{mg} \cdot \mathrm{L}^{-1}$ & $91.4 \pm 1.8 \mathrm{a}$ & $71 \pm 5.6 \mathrm{a}$ & $29 \pm 4.0 \mathrm{c}$ \\
\hline
\end{tabular}

Means within a row followed by different superscripts are different at $P=0.05$ (t-test) by DPS software (v13.5).

${ }^{z}$ Data followed by different letters in the same column were significantly different at $P \leq 0.05$ by Duncan's new multiple range test.

Table 4. Effect of different embryo germination media on the abnormal plantlet formation (means \pm SD).

\begin{tabular}{lccc}
\hline \hline Media & Germination rate (\%) & Normal plantlets (\%) & Abnormal plantlets (\%) \\
\hline WPM + 6-BA $0.2 \mathrm{mg} \cdot \mathrm{L}^{-1}$ & $91.1 \pm 1.7 \mathrm{a}^{\mathrm{z}}$ & $55 \pm 4.0 \mathrm{~b}$ & $45 \pm 5.3 \mathrm{a}$ \\
WPM + 6-BA $0.2 \mathrm{mg} \cdot \mathrm{L}^{-1}+\mathrm{ZnSO}_{4} 10 \mathrm{\mu mol} \cdot \mathrm{L}^{-1}$ & $91.3 \pm 1.7 \mathrm{a}$ & $63 \pm 5.6 \mathrm{ab}$ & $37 \pm 2.6 \mathrm{ab}$ \\
WPM + 6-BA $0.2 \mathrm{mg} \cdot \mathrm{L}^{-1}+$ mashed-banana $500 \mathrm{mg} \cdot \mathrm{L}^{-1}$ & $93.4 \pm 1.1 \mathrm{a}$ & $68 \pm 4.6 \mathrm{a}$ & $32 \pm 4.4 \mathrm{~b}$
\end{tabular}

Means within a row followed by different superscripts are different at $P=0.05$ (t-test) by DPS software (v13.5).

${ }^{z}$ Data followed by different letters in the same column were significantly different at $P \leq 0.05$ by Duncan's new multiple range test. 
seedlings with healthy stems and leaves; 2) many buds clustered around the tissue; 3 ) dedifferentiation and formation callus (Fig. 3). Generally, these abnormal plantlets can develop as normal healthy plants after transferring the clustered buds or the transformed normal seedlings to the rooting media for two weeks.

Three kinds of transformation mediums were set (Table 5). We have obtained the normal seedlings after transforming the abnormal seedlings onto the conversion media " $2 \mathrm{MS}$ + 6-BA $0.4 \mathrm{mg} \cdot \mathrm{L}^{-1}+\mathrm{IBA} 0.1 \mathrm{mg} \cdot \mathrm{L}^{-1}+\mathrm{ZnSO}_{4} 10 \mu \mathrm{mol} \cdot \mathrm{L}^{-1,}$, of which the transformation rate was $27.9 \%$, or " $2 \mathrm{MS}+$ 6-BA $0.4 \mathrm{mg} \cdot \mathrm{L}^{-1}+\mathrm{IBA} 0.1 \mathrm{mg} \cdot \mathrm{L}^{-1}+$ mashed-banana 500 $\mathrm{mg} \cdot \mathrm{L}^{-1}$, , of which the transformation rate was $21.0 \%$. It was worth to mention that the abnormal seedlings could be converted to normal seedlings on control media " $2 \mathrm{MS}$ +6 -BA $0.4 \mathrm{mg} \cdot \mathrm{L}^{-1}+\mathrm{IBA} 0.1 \mathrm{mg} \cdot \mathrm{L}^{-1}$, , although that was

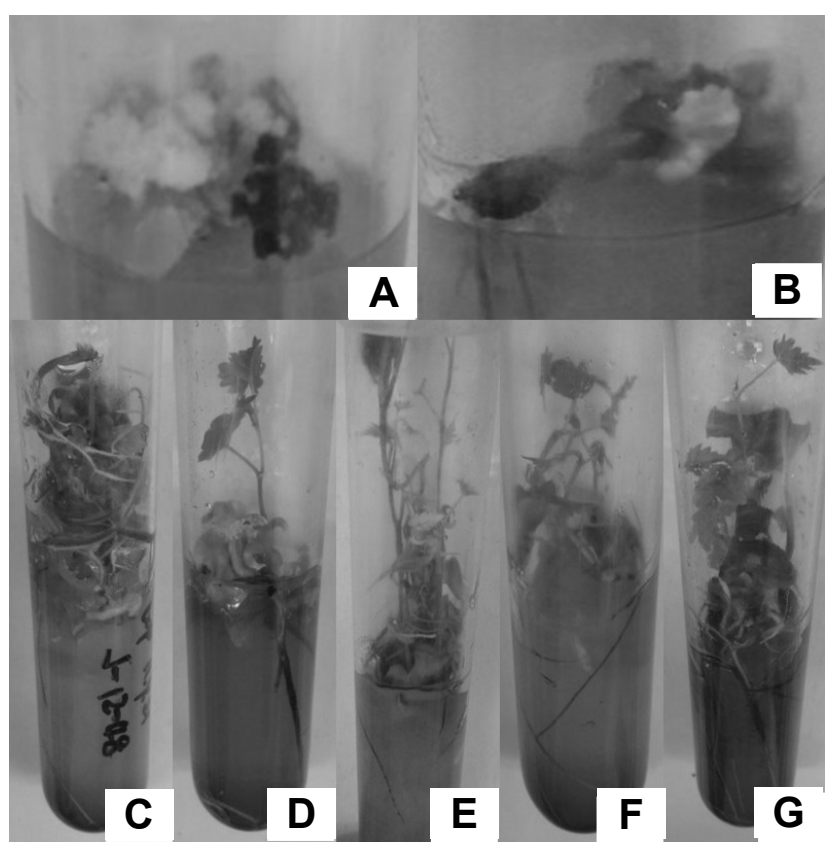

Fig. 3. The conversion of the abnormal seedlings: (A) Dedifferentiation and formation callus; (B) Many buds clustered around the tissue; (C-E) Induced the abnormal seedlings which cotyledons were distorted fold-like into normal seedlings with healthy stems and leaves; (F-G) Induced the abnormal seedlings which epicotyl appears only one cotyledon into normal seedlings. only $12.0 \%$. It suggested that maybe transferring the abnormal seedlings onto the suitable fresh media was an effective way to transform them into normal seedlings.

\section{Conclusion}

The formation of abnormal seedlings were emerged mainly from the female parent genotype rather than that from the pollen parents. Polyembryony was advantageous to diminish the number of abnormal plantlets and to promote the germination rate up to $100 \%$. The pre-chilling treatment reduced the number of abnormal plantlets, at the same time, promoted the embryo germination. The abnormal plantlets were reduced significantly by the addition of $\mathrm{ZnSO}_{4} 10 \mu \mathrm{mol} \cdot \mathrm{L}^{-1}$ or 500 $\mathrm{mg} \cdot \mathrm{L}^{-1}$ mashed-banana in comparison with the control. Transferring the abnormal seedlings onto the suitable fresh media in 4 weeks after embryo germination was an effective way to transform them into normal seedlings.

\section{Discussion}

In this study, we found that not all of the embryos formed normal seedlings after embryo germination, which is consistent with the results of previous reports (Emershad and Ramming, 1984; Liu et al., 2003; Ponce et al., 2002; Tian et al., 2008; Valdez, 2005). Our results clearly demonstrated that abnormal seedling rate was influenced by genotype (Table 1). The formation of abnormal seedlings was mainly determined by female parent genotype rather than that of pollen parents. It indicated that different variety has the different adaptability for embryo rescue. This adaptability could be controlled by the specific genotype, like some other cultivars in earlier findings (Goldy et al., 1987; Ponce et al., 2000; Tang et al., 2009; Tian et al., 2008). As was stated by Liu et al. (2003), the occurrence of abnormal seedlings in the process of embryo rescue may be related to the development level of the embryo. Valdez (2005) also pointed out that direct germination was not recommended since most of the normal plantlets $(80 \%)$ came from excised embryos. The final percentage of plantlets from directly germinated embryos after $240 \mathrm{~d}$

Table 5. The transformation test of the deformity seedlings (means $\pm S D$ ).

\begin{tabular}{lrrr}
\hline \hline \multirow{2}{*}{ Media } & No. of abnormal & \multicolumn{2}{c}{ Transformation plantlets } \\
\cline { 2 - 4 } & plantlets & No. & $(\%)$ \\
\hline $2 \mathrm{MS}+6-\mathrm{BA} 0.4 \mathrm{mg} \cdot \mathrm{L}^{-1}+\mathrm{IBA} 0.1 \mathrm{mg} \cdot \mathrm{L}^{-1}$ & $11 \pm 4.4 \mathrm{~b}^{2}$ & $1 \pm 1.0 \mathrm{~b}$ & $12.0 \pm 12.5 \mathrm{a}$ \\
$2 \mathrm{MS}+6-\mathrm{BA} 0.4 \mathrm{mg} \cdot \mathrm{L}^{-1}+\mathrm{IBA} 0.1 \mathrm{mg} \cdot \mathrm{L}^{-1}+\mathrm{ZnSO}_{4} 10 \mathrm{\mu mol} \cdot \mathrm{L}^{-1}$ & $23 \pm 3.6 \mathrm{a}$ & $6 \pm 2.6 \mathrm{a}$ & $27.9 \pm 17.1 \mathrm{a}$ \\
$2 \mathrm{MS}+6-\mathrm{BA} 0.4 \mathrm{mg} \cdot \mathrm{L}^{-1}+\mathrm{IBA} 0.1 \mathrm{mg} \cdot \mathrm{L}^{-1}+\mathrm{mashed}-\mathrm{banana} 500 \mathrm{mg} \cdot \mathrm{L}^{-1}$ & $19 \pm 2.6 \mathrm{a}$ & $4 \pm 1.7 \mathrm{ab}$ & $21.0 \pm 8.1 \mathrm{a}$ \\
\hline
\end{tabular}

Means within a row followed by different superscripts are different at $P=0.05$ (t-test) by DPS software (v13.5).

${ }^{z}$ Data followed by different letters in the same column were significantly different at $P \leq 0.05$ by Duncan's new multiple range test. 
was $24.5 \%$, but an abnormality of $57 \%$ was found.

During the process of the embryo rescue, we also observed polyembryony in several crosses when ovules were excised. After in vitro culture, we found that polyembryony was benefit for diminishing the number of abnormal plantlets by successive transferring embryos to fresh media and the germination rate of polyembryony was $100 \%$. It supports the conclusion that polyembryony is advantageous to diminish the number of abnormal plantlets in the Superior Seedless $\times$ Dawn Seedless cross (Valdez, 2005). As was described by Mariscalco and Crespan (1995) that polyembryony might depend on genotype $\mathrm{RxD}<\mathrm{RxC}<\mathrm{BrxCr}<\mathrm{Bx} 73<\mathrm{CrxMl}$ $<$ CrxSe $<\mathrm{SxD}<\mathrm{FxBe}$. In this experiment, polyembryony occurred in the cross combinations "Ruby Seedless $\times$ Black Olympia", "Ruby Seedless self-pollination" and "Otilia Seedless self-pollination" and "Superior Seedless self-pollination", but the appearance of that was in a slim chance.

We noted that the low-temperature treatment could reduce the occurrence of abnormal seedlings. It led to percentage of abnormal seedling rate of $36.0 \%$, significantly lower than that of the control (46.9\%). Meanwhile, low-temperature treatment increased the embryo germination rate. So it was benefit for promoting the efficiency of embryo rescue (Table 2), further suggesting that low temperature could help to break seed dormancy. Sharma et al. (1996) stated that embryos that were not subjected to low temperature exhibited low vitality and germination, produced plants with deformed leaves of rosette growth and quickly passed into a dormant stage, and if the embryos were placed into a cooling box at $1-5^{\circ} \mathrm{C}$ after their transfer to a nutrient medium for a period of at least 40 days, they formed normal growing seedlings. Anderson et al. (2002) also reported that cooler temperature during germination improves the survival of embryo cultured peach seed.

In natural conditions, no seedlings were obtained from various crosses with stenospermocarpic grapes. The exact reason for embryo abortion is unclear, although in vitro culture has been applied in breeding. Poor germination of seeds from early ripening grapes is probably due to poor embryo development. A fact that the breakdown of endosperm prior to embryos was observed in vivo, inferring that a nutrient deficiency occurred during embryo development (Raghavan, 1966; Stout, 1939). Nutrient analysis revealed high levels of amino acids in the endosperm tissue (Smith, 1973). Tian et al. (2008) stated that ovules response to amino acids differently. This enhanced the application of these compounds in the medium (Emershad and Ramming, 1984; Emershad et al., 1989). These supports our results that the abnormal plantlets were reduced significantly by addition of $\mathrm{ZnSO}_{4}(24 \%)$ or mashed-banana (29\%) in comparison with MS (43\%). At the same time, the highest embryo germination (91.4\%) was found when ovules were cultured in MS + mashed-banana $500 \mathrm{mg} \cdot \mathrm{L}^{-1}$. This may be attributed to a variety of nutrients contained in banana. Additionally, mashed-banana is a kind of natural organic additives which provides amino acids and trace elements required for plant growth. In this experiment, the addition of PGRs $\left(\mathrm{GA}_{3} 10 \mu \mathrm{mol} \cdot \mathrm{L}^{-1}+\mathrm{IAA} 10 \mu \mathrm{mol} \cdot \mathrm{L}^{-1}\right)$ to MS media affected the embryo germination adversely and also stimulated the formation of abnormal plantlets. It is inconsistent with previous studies by Gray et al. (1990) and Yamashita et al. (1998). Palmer et al. (2002) also obtained the similar results in Vigna that a medium containing MS basal nutrients with sucrose $(88 \mathrm{mM})$, casein hydrolysate $\left(500 \mathrm{mg} \cdot \mathrm{L}^{-1}\right)$ and agar $\left(8 \mathrm{~g} \cdot \mathrm{L}^{-1}\right)$ but devoid of plant-growth regulators was found to be the best for germination of immature embryos for all four Vigna species investigated. Leshem et al. (1985) suggested that the induction and abnormal traits of abnormal plants could be due to imbalance of auxins and cytokinins. So the type and quantity of the application of PGRs is our further job.

As to the deformity seedlings emerged in a large chance in plant tissue culture, it severely restricted the development of grape breeding by embryo rescue techniques. In view of the principle of saving of human and financial resources, the way to discard them is not recommended, but the appropriate corrective and prevention is advisable. We firstly classified the abnormal seedlings into seven categories which were produced in the process of seedless grape breeding by embryo rescue. The occurrence and proportion of each variety of malformation seedlings are random and unfixed. The conversion test of abnormal seedlings produced in the process of embryo rescue was also conducted in this experiment (Table 4). We obtained the transformed plants by transferring the abnormal seedlings to the transformation media. It is worth mentioning that the transformation of the abnormal seedlings only can be transformed in the certain period (data was not shown), that is to say, if the best transformed time (4 weeks after embryo germination) was missed, the conversion of the abnormal seedlings will be impracticable.

In fact, breeding for stenospermic grapes by embryo rescue is a long-term task. Discarding the abnormal seedlings is undesirable, and the key is appropriate corrective and prevention. We have to point out this study is only a preliminary report. For other factors, such as sampling time, the addition of mineral nutrients and plant growth regulators on medium could also influence the breeding efficiency by affecting the abnormal seedling rates with complex interactions. The preliminary transformation test was conducted in this experiment, and test on the kind and concentration of natural organic additives is our further job. With the increasing number of progenies 
in our laboratory, further experiments on various parameters are in progress. From the results obtained, this research can clearly indicate the feasibility and perspective of our protocol.

\section{Literature Cited}

Anderson, N., D.H. Byrne, J. Sinclair, and A.M. Burrell. 2002. Cooler temperature during germination improves the survival of embryo cultured peach seed. HortScience 37:402-403.

Bharathy, P.V., U.S. Karibasappa, S.G. Patil, and D.C. Agrawal. 2005. In ovulo rescue of hybrid embryos in flame seedless grapes-Influence of pre-bloom sprays of benzyladenine. Sci. Hort. 106:353-359.

Emershad, R.L. and D.W. Ramming. 1984. In-ovulo embryo culture of Vitis vinifera LCV 'Thompson seedless'. Am. J. Bot. 71:873-877.

Emershad, R.L., D.W. Ramming, and M.D. Serpe. 1989. In ovulo embryo development and plant formation from stenospermic genotypes of Vitis vinifera. Am. J. Bot. 76:397-402.

Goldy, R.G. and U. Amborn. 1987. In vitro culturability of ovules from 10 seedless grape clones. HortScience 22:952.

Gray, D.J., J.A. Mortensen, and C.M. Benton. 1990. Ovule culture to obtain progeny from hybrid seedless bunch grapes. J. Am. Soc. Hort. Sci. 115:1019-1024.

Gribaudo, I., R. Zanetti, R. Botta, R. Vallania, and I. Eynard. 1993. In ovulo embryo culture of stenospermocarpic grapes. Vitis 32:9-14.

Leshem, B. and T. Sachs. 1985. 'Vitrified' Dianthus-teratomata in vitro due to growth factor imbalance. Ann. Bot. 56:613-617.

Liu, S.M., S.R. Sykes, and P.R. Clingeleffer. 2003. Improved in ovulo embryo culture for stenospermocarpic grapes (Vitis vinifera L.). Aust. J. Agr. Res. 54:869-876.

Lloyd, G. and B. McCown. 1980. Commercially feasible micropropagation of mountain laural, Kalmia latifolia, by use of shoot-tip culture. P. Int. Plant Prop. Soci. 30:421-427.

Mariscalco, G. and M. Crespan. 1995. Polyembryony and somatic embryogenesis of in vitro cultured in ovulo embryos of seedless grapes. Die Weinwissenschaft 50:39-43.

Palmer, J.L., R.J. Lawn, and S.W. Adkins. 2002. An embryo-rescue protocol for Vigna interspecific hybrids. Aust. J. Bot. 50: 331-338.

Park, S.M., M. Hiramatsu, and A. Wakana.1999. Aneuploid plants derived from crosses with triploid grapes through immature seed culture and subsequent embryo culture. Plant Cell Tiss.
Org. Cult. 59:125-133.

Ponce, M.T., C.B. Agüero, M.T. Gregori, and R. Tizio. 2000. Factors affecting the development of stenospermic grape (Vitis vinifera L.) embryos cultured in vitro. Acta Hort. 528:667-671.

Ponce, M.T., M.E. Guinazu, and R. Tizio. 2002. Brief Note Improved in vitro embryo development of stenospermic grape by putrescine. Biocell 26:263-266.

Raghavan, V. 1966. Nutrition, growth and morphogenesis of plant embryos. Biological Rev. 41:1-58.

Ramming, D.W. and R.L. Emershad. 1982. In ovulo embryo culture of seeded and seedless Vitis vinifera L. HortScience 17:487.

Sharma, D.R., R. Kaur, and K. Kumar. 1996. Embryo rescue in plants-A review. Euphytica 89:325-337.

Singh, N.V., S.K. Singh, and A.K. Singh. 2011. Standardization of embryo rescue technique and bio-hardening of grape hybrids (Vitis vinifera L.) using Arbuscular mycorrhizal fungi (AMF) under sub-tropical conditions. Vitis 50:115-118.

Smith, J.G. 1973. Embryo development in Phaseolus vulgaris II. Analysis of selected inorganicions, ammonia, organic acids, amino acids, and sugars in the endosperm liquid. Plant Physiol. 51:454-458.

Spiegle-Roy, P., P.N. Sahar, and J. Baron. 1985. In vitro culture and plant formation from grape cultivars with abortive ovules and seeds. J. Am. Soc. Hort. Sci. 110:109-112.

Steward, F.C., M.O. Mapes, and J. Smlth. 1958. Growth and organized development of cultured cells. I. Growth and division of freely suspended cells. Am. J. Bot. 45:693-703.

Stout, A.B. 1939. Progress in breeding for seedless grapes. P. Am. Soc. Hort. Sci. 37:627-629.

Tang, D.M., Y.J. Wang, J.S. Cai, and R.H. Zhao. 2009. Effects of exogenous application of plant growth regulators on the development of ovule and subsequent embryo rescue of stenospermic grape (Vitis vinifera L.). Sci. Hort. 120:51-57.

Tian, L.L. and Y.J. Wang. 2008. Seedless grape breeding for disease resistance by using embryo rescue. Vitis 47:15-19.

Tian, L.L., Y.J. Wang, L. Niu, and D.M. Tang. 2008. Breeding of disease-resistant seedless grapes using Chinese wild Vitis spp. I. In vitro embryo rescue and plant development. Sci. Hort. 117:136-141.

Valdez, J.G. 2005. Immature embryo rescue of grapevine (Vitis vinifera L.) after an extended period of seed trace culture. Vitis 44:17-23.

Yamashita, H., I. Shigehara, and T. Haniuda. 1998. Production of triploid grapes by in ovule embryo culture. Vitis 37:113-117. 